\title{
INTRODUÇÃO AO MÉTODO BIOGRAFEMÁTICO
}

Sandra Mara Corazza*

* sandracorazza@terra.com.br

Professora titular da FACED/UFRGS. Experimentadora de Escrileituras em Filosofia-Educação, Literatura-Artes, Currículo da Diferença, Didática da Tradução. Publicou, entre outros: Para uma filosofia do inferno na educação: Nietzsche, Deleuze e outros malditos afins (2002); Artistagens: filosofia da diferença e educação (2006), Os cantos de Fouror: escrileitura em filosofia-educaçao (2008), Abecedario: educaçăo da diferença (2009, coautoria), Dicionário das idelas feitas em
educação (2011) e O que se transcria em educação? (2013).

$\S 1^{\circ}$. Senhores, A razão que me leva a apresentar-vos esta obra é tão justa - e quando conhecerdes seu desígnio, estou certo de que terei o também justo desígnio de tomá-la sob vossa proteção - que penso nada melhor poder fazer, para torná-la de algum modo recomendável a vossos olhos, do que dizer-vos, em poucas palavras, o que me propus nela (Descartes, 1962b, p.105)

\section{DIS-CURSUS DO MÉTODO}

Art. 1. Método, aqui, dista de doutrina e de processo técnico; de sistema, como "aspecto de conteúdo", e do próprio método, como "aspecto formal" (Brugger, 1962, p.345); de leis científicas e da natureza reta da faculdade de conhece

superior (cf. Deleuze, 1994); do modelo matemático e das regras da lógica formal; de garantias analíticas e sintéticas sobre o Conhecimento da Verdade.

Art. 2. Método é tomado como meta + hodós (= por essa via): "uma direção definível e regularmente seguida numa operação do espírito” (Lalande, 1999, p.679).

Art. 3. Como "procedimento de pesquisa" (Abbagnano, 1970), este Método segue orientações: (a) não é determinado a priori, nem independentemente da sua aplicação, feito um programa de operações, iniciadas só após a formulação de regras (cf. Brugger, 1962); (b) faz-se em operações efetivas, que 
o fazem à medida que se fazem; (c) percurso de conhecimento biografemático, estabelece-se "como criação e não como descoberta", desde que "o percurso é conhecer; seu método, a criação, o ensaio"; (d) se produz algum saber, este nada mais é do que "uma perspectiva entre outras e não, ao estilo metafísico, o conhecimento único e eterno sobre a realidade" (Monteiro e Biato, 2008, p. 270; p.267); (e) logo, não é Método ordenado, repetível, autocorrigível; (f) se transferido para outras operações de pensamento, pode suceder até a inutilização dos esforços feitos para obter resultados válidos.

Art. 4. Introdução ao método biografemático (de agora em diante, denominado IMB) deixa-se guiar, virgilianamente, por Roland Barthes (1979; 1982; 1984; 1988; 1989a,b; 1991 2003a,b; 2005a,b; 2008)

Art. 5. Mostra que Método: (a) "não pode ter por objeto senão a própria linguagem", na medida em que "luta para baldar todo discurso que pega"; (b) "é uma ficção", que segue "o método da linguagem", como "a linguagem se refletindo"; (c) enquanto Método de "desprendimento", busca "manter um discurso sem o impor"; (d) pois "não pode realmente ter por objeto senão os próprios meios para baldar, desprender ou pelo menos aligeirar" o poder das "formas discursivas", através das quais "ele mesmo é proposto" (Barthes, 1989a p.42-43)
Art. 6. IMB será apreciada por quem já tenha, alguma vez, se interessado por Vida (Biografia) e por Obra (Bibliografia). Só que, em vez de Vida e Obra, tomadas em separado, ou uma como derivada e mesmo causa da outra, trata de Vidarbo: (a) por meio de Atos de Mutação - engajados na mentira, no disfarce, no mascaramento -, põe Vida na Obra; (b) via divisão e despersonalização do Sujeito que vive e escreve, realiza Escrita de Vida; (c) através da fragmentação do Autor da Vida, cria o Narrador da Obra; (d) pela pulverização do Narrador da Obra, inventa o Autor da Vida; (e) como Escritura de Vida ("escritura sem piscar os olhos"), “risca', inscreve, traça, ocupa o terreno do Tempo por uma energia de inscrição, inteiramente perversa" (Barthes, 2004c, p.287 2005b, p.156).

Art. 7. Brada: - Tenho, no mínimo, um Eu a zerar!

Art. 8. - Há, em mim, IMB, Prazer do Texto, que transmigra para a Vida. - Há escrita de Outrem, como Mundo Possível (cf. Deleuze, 1998), que reelabora fragmentos de cotidianidade. - "Todo fragmento é acabado, a partir do momento em que é escrito”. - Ah, a grandeza das obras fragmentárias - "Não grandeza da ruína ou da promessa, mas grandeza do silêncio que acompanha todo acabamento" (Barthes, 2004c, p.282-283). - "Será aí, no fragmento arruinado da linguagem, que se encontra o real da ficção? Ou, quem sabe, o real da realidade" (Nolasco, 2004, p.14)? - Face à ficção, não exigimos 
"que ela tenha realidade"? - Para além da demanda por "efetuação de realidade" (Ribeiro, 1988, p.21), existe um índice para o Prazer do Texto? - Aquele que diz: Poder viver com.. - Viver com um Autor, embora a vida seja "feita a golpes de pequenas solidões" (Barthes, 1984, p.11). - Não realizar, na Vida do Leitor, um programa traçado pelo Autor, senão passar para a sua cotidianidade fragmentos de inteligível, forjados nos textos admirados. - O Autor "não descobre (sob a ação de uma subjetividade privilegiada) que o mundo é desejável, ele o determina desejável". - Não "narra o que vê, o que sente, não desenrola os preciosos epítetos que tem a felicidade de encontrar". - Também não "age como psicólogo que se servisse de uma linguagem feliz para enumerar os atributos originais de sua visão". - O Autor "age imediatamente como escritor". - Cria "uma vasta metonímia do desejo: escrita contagiosa que faz recair sobre o leitor o desejo mesmo com que formou as coisas" (Barthes, 2004c, p.292). - Não é necessário "acrescentar coisas suas a um texto para o 'deformar'; basta citá-lo, isto é, cortá-lo: um novo inteligível nasce imediatamente" (Barthes, 2003b, p.229). - Não aplicar procedimentos, mas fazê-los falar. - "A vida [biós] bios, ela se escreveria" (Fabbrini, 1996, p.65)? - Talvez deixando ao Biografema (daqui para frente, chamado Ba) distância das citações, força de irrupção das palavras, explosão vulcânica das verdades de linguagem. - A Vida Cotidiana torna-se, assim, um teatro. - E "o cotidiano vacila na ambigüidade de seu movimento" (Oliveira,
2008, p.10). - Se vivo com Nietzsche, falo nietzschiano; se vivo com Deleuze, falo deleuziano; se vivo com Flaubert, falo flaubertiano. - O Texto emite ordens fantasísticas (fantasmáticas). - Para tanto, a idéia de Autor voltou à cena com algum valor. - Mas não Autor chapado em documentos de identidade. - Nem Herói das Biografias. - Ou o Grande Narcisista das Autobiografias. - Nem Mortos Famosos. - Ou Mestres Imortais. - Nem Biografias que funcionam como auto-ajuda, modelos, janelas indiscretas para o voyeurismo. - Muito menos ícones para sedentos Ideais-do-Eu. - O Autor, que salta de seus textos e entra na Vida do Leitor, não tem unidade. - É um simples plural de encantos, lugar de pormenores sutis, fonte de vivos clarões romanescos, canto descontínuo de amabilidades. - O "canto não é uma eufonia ou uma qualidade das imagens, é, segundo o mito órfico, uma maneira de manter o mundo sob sua linguagem" (Barthes, 2004c, p.292). - Definitivamente, não se trata de uma pessoa civil, moral, mas de um corpo. - Ora, "é o impessoal que lança, como uma flecha sempre retomada, retornada, um eu sem pessoa, que só tem a individualidade da mão corporal que escreve; a substância que separa as duas pessoas da narração não é de identidade em nenhum lugar, mas apenas de anterioridade: ele é cada vez aquele que vai escrever eu; eu é cada vez aquele que, começando a escrever, vai no entanto entrar na pré-criatura que lhe deu origem" (Barthes, 1982, p.23-24). 
Art.9. Introdução ama: (a) o Prazer do Texto e o amigável (e deformado) regresso do Autor; (b) o Sujeito outra vez, embora desfeito, para readequar os Planos de Vida (não de Escrita com Vida, que resulta em Biografia); (c) as intersecções entre Vida e Escrita dos "Logotetas, dos fundadores de línguas" (Barthes, 1979, p.9); (d) a não parecença da Obra com a Vida mas Escrita conduzindo Vida; (e) a Biografemática (denominada Bat) que, quanto mais fragmenta Escrita e Vida, mais torna cada fragmento homogêneo (" $U m$ fragmento de escritura é sempre uma essência de escritura") (Barthes, 2004c, p.282); 2; (f) a tipologia dos Eus (cintilações) que escrevem: Persona (pessoa cotidiana); Scriptor (imagem social); Auctor (fiador do que escreve); Scribens (que vive escrevendo) (Barthes, 2005b p.173-174); (g) o processamento de uma "casuística do egoísmo" (cf. Nietzsche, 1995, p.50), por intermédio de uma "Vida Metódica" (Barthes, 2005b, p.175; p.201; p.205).

Art. 10. - Método opera: (a) "ao escrever, a fragmentação, e ao expor, a digressão ou, para dizê-lo por uma palavra preciosamente ambígua: a excursão" (Barthes, 1989a, p.43-44); (b) disseminação dos traços de antigos textos da cultura - "pertinentes e por isso mesmo descontínuos" (Barthes, 2003a p.330), através de fórmulas irreconhecíveis, disfarçadas como mercadorias roubadas; (b) apagamento da falsa eflorescência sociológica, histórica, subjetiva de determinações, estruturas, visões, projeções dos textos; (c) ostentação vitoriosa de textos nômades, para que se desliguem (como de pele malsã) dos sentidos recebidos, que buscam recobri-los; (d) recusa a inferir Autor da Obra e Obra do Autor; (f) posicionamento no Mundo do Autor e descrição de "sua população", sem referência a fontes exteriores; (g) abalo dos sentidos do mundo, pela colocação de uma interrogação indireta, que sofre abstenção de resposta única; (1) afirmação, antagonismo e substituição de várias respostas que passam, enquanto a interrogação permanece (não paramos de responder ao que foi escrito fora de qualquer resposta) (cf. Barthes, 2008, p.VII-XI).

Art. 11. Biografemática afirma: (1) Bat é Filosofia, Ciência e Arte: "jogo de imagens, de espelhos" do que é "colhido numa narrativa, num texto" (Barthes, 2003a, p.212). (2) Quem realiza Bat é Biografólogo (chamado Bo). (3) Bo coleta e cria Biografemas (doravante, grafado Bas). (4) O Ba da Bat é um traço distintivo, um elemento quase-unitário, que finge que revela. (5) Ba, Bat, Bo: grandes mentirosos ontológicos, que emitem raios radioativos. (6) Sem documentos, não há Bat, nenhum Ba, nada de Bo. (7) Bas já montados, no Bastidor Biografemático (BB), resultam numa Biodiagramação (Bão) (cf. Pignatari, 1996). (8) Bão dá visão do conjunto de UmaVida (U-V) (cf. Deleuze, 2007). (9) U-V não se faz com "o 'vivido' (o 'vivido' é banal e é justamente ele que o escritor deve combater)", nem, tampouco, com "a razão (categoria geral adotada sob diversos artifícios por todas as literaturas 
fáceis)" (Barthes, 2004c, p.290). (10) Ao realizar "a utopia de uma linguagem particular”, a substância de U-V é constituída por espaços vazios, flutuantes, lacunas, incidentes, punctuns. (11) U-V não é veraz da mesma maneira que Bat não é imaginária: trata-se da Bat veraz de U-V imaginária.

Art. 12. IMB, portanto, fica e não fica na vizinhança de um Manual, de uma Quimera, do Anarquismo (cf. Feyerabend 1989). Pois essa não é uma questão digna de ser enunciada e resolvida. Giza "que a obra constitui apenas uma Introdução" (Descartes, 1962a, p.39) e que seu Método não é "heurístico que visaria a produzir deciframentos e apresentar resultados" (Barthes, 1989a, p.42). IMB terá atingido as fimbrias da perfeição, se fornecer energia vital àquele Pensador que a experimentar.

$\S 2^{\circ}$. Os decimais que numeram os Operadores deste Método, em cada uma de suas duas Partes iniciais (a Terceira Parte não é numerada, por cansaço; já a Quarta vem apresentada em or dem alfabética), indicam o peso valorativo e, logo, a importância que possuem para Bat. Os Operadores n.1, n.2, n.3, etc. são observações relativas ao Operador $n^{\circ} n$; os Operadores n.m.1, etc. são observações relativas ao Operador $n^{0} n . m$; e assim por diante ( $c$. Wittgenstein, 1993, p.135)

\section{PRIMEIRA PARTE. DA FANTASIA}

1 Tudo parte deste princípio: na origem de Bat, "como engendramento de formas, de diferenças", "é preciso aceitar que se coloque" "sempre uma fantasia" (um fantasma) - bem como "na origem de uma pesquisa", "na origem de um ensino", na "origem da cultura" (Barthes, 1989a, p.44; 2003a, p.8; p.273).

1.1 Pois, "qual prazer maior que a realização de uma fantasia" (Barthes, 2003d, p.284)?

1.11 Mesmo sendo apenas "um germe, uma virtualidade" (Barthes, 2005a, p.117), aí mora Fantasia de Bat (FB); logo existirá Bat.

1.2 O que chamamos Bat consiste num objeto fantasístico (fantasmático), que "não quer ser assumido por uma metalinguagem (científica, histórica, sociológica)” (Barthes, 2005a, p.23)

1.21 Bat: "Utopia, Fantasia, Soberano Bem" (Barthes, 2005a, p.206).

1.211 Originalidade e radicalismo fantasístico de Bat: "em se tratando ao menos dos problemas da discursividade", "as pessoas estudam o que desejam ou o que temem" (Barthes, 2003d, p.430). 
1.3 Há generosidade de Bat, desde que (como o Romance) é uma "prática para lutar contra a secura do coração, a acídia": "ama o mundo", "o abarca e abraça" (Barthes, 2005a, p.29).

1.31 Aquilo que colore Bat é a pulsão de amor.

1.311 Bat é fantasiada como "ato de amor": (a) não na direção do "Amor apaixonado= falar de si como apaixonado = lírico"; (b) mas do "Amor-Agápe: falar dos outros que se ama", "dizer aqueles que se ama"; (c) de maneira que "Amar + escrever = fazer justiça àqueles que conhecemos e amamos, isto é, testemunhar por eles, (no sentido religioso), isto é, imortalizá-los" (Barthes, 2005a, p.28).

1.3111 Com Bat, escrevemos aqueles que amamos.

1.4 FB serve, assim, de "Guia Iniciático" para Bat (Barthes, 2005a, p.22).

1.41 FB tem "ardor de desejo e tende a se alargar, a se ultrapassar, a se sublimar" (Barthes, 2005a, p.27).

1.42 FB: (a) "não é dialética"; "não é uma contranegação"; não é "o direito de uma frustração vivida como avesso"; "não é o contrário de seu contrário racional, lógico”; (b) no caso de Fantasias de Bat negativas, não se trata de oposição entre "uma imagem e uma realidade", mas da existência de "duas imagens fantasmáticas" ou de "dois roteiros imaginários"; (c) pois FB é um "= enredo breve, enquadrado" (Barthes, 2005a, p.117); "roteiro absolutamente positivo, que encena o positivo do desejo, que só conhece positivos"; "roteiro, mas roteiro estilhaçado, sempre muito breve"; como "vislumbre narrativo do desejo": o que "se entrevê, muito recortado, muito iluminado, mas imediatamente esvaecido"; "uma volta de desejos, de imagens, que rondam, que se buscam em nós, por vezes durante uma vida toda, e freqüentemente só se cristalizam através de uma palavra"; (d) uma "palavra, significante maior", que "induz da fantasia à sua exploração", "por diferentes bocados de saber = a pesquisa"; (e) fantasia, como "um filme com tomadas fixas" (Barthes, 2005b, p.177); (f) que é então explorada "como uma mina a céu aberto" (Barthes, 2003a, p. 9-10; p.12; p.35).

1.5 FB exerce sua força fantasística como Fantasia de Escritura, dentre outras (cf. Barthes, 2003a, p.84-85; p.89; p.152; p.251-252; p.283-284; p.290-291; 2003d, p.304 2005a, p.15; p.20-22; p.27; p.273).

1.51 Para Bat, "é preciso haver cenário, portanto lugar" (Barthes, 2003a, p.14).

1.511 Assim, FB funciona como: (a) um "projetor incerto que varre, de modo entrecortado, fragmentos de mundo, de ciência, de história - de experiências"; (b) "um projetor nítido, poderoso, seguro, que recorta a cena iluminada onde o desejo se instala e deixa na sombra os dois lados da cena" (Barthes, 2003a, p.17; p.35). 
1.5111 Para se movimentar, FB: (a) "deve ficar ligada a uma imagem grosseira, codificada: o Poema, o Romance"; (b) assim, "como uma energia, um motor", FB "põe em marcha" (c) só que aquilo que FB produz, a seguir, "não depende mais do Código" (Barthes, 2005a, p. 22).

1.52 Ao lutar e se chocar (prática de Bat) com o Real - que "é o Tempo (a Duração) como potência de atraso, de freagem, e portanto de modificação, de infidelidade" (Barthes, 2005b, p.277) -, FB "se perde como fantasia", abandona " rigidez da Fantasia", "a ingenuidade da Fantasia”, a "virtualidade da Fantasia” (Barthes, 2005a, p.22; p.25; p.117).

1.521 Só então pode atingir "o Sutil, o Inédito" (Barthes, 2005a, p.22).

1.6 O Querer-Escrever (Scripturire) de FB é que recolhe "a extrema subjetividade, pois na escritura há um acordo entre o indireto da expressão e a verdade do sujeito (Barthes, 2003a, p.257).

1.7 Desde FB, Bat (d)escreve "carências", "impossibilidades (aporias) cuja única positividade é a tensão (a intensidade)" (Barthes, 2003d, p.71).

1.71 A Escritura de Bat (EB): (a) talvez seja "uma força terrível, imperiosa, corajosa, de de-cepção"; (b) por ela, "algo opera, mas não é um efeito"; (c) talvez, um "ato complexo e completo"; (d) ou mesmo, como a própria "definição da escritura: algo divino (esse Signo), epifania" (Barthes, 2005a, p.139; p.140; p.189; p. 150).

1.8 Vê-se como o Texto (Tecido) de EB se relaciona com a Verdade: (a) principia "não pelo falso, mas quando se misturam, sem prevenir, o verdadeiro e o falso: o verdadeiro gritante, absoluto, e o falso colorido, brilhante, vindo da ordem do Desejo e do Imaginário"; (b) compõe assim uma "vasta e longa tela pintada de ilusões, de logros, de coisas inventadas, de 'falsidades': tela brilhante, colorida, Véu da Maia"; (c) "seria poikilos, estampado, variado, mosqueado, sarapintado, coberto de pinturas, de quadros, vestimenta bordada, complicada, complexa; raiz pingo [pintar], bordar com fios diversos, tatuar"; (d) como "o poikilos do romance = um heterogêneo, um heterológico de Verdadeiro e de Falso" (Barthes, 2005a, p.224).

\$3. Todavia, em qualquer análise, é sempre indispensável, antes de tudo, estar de acordo sobre o seu próprio objeto servindo-nos de razões que o definam - e não apenas sobre o seu nome, sem preocupar-nos com a sua definição. Não é nada fácil saber o que são as pessoas, objeto de nossa análise, e dizer o que é o sofista. Mas, o método aceito por todos, e em todo lugar, para levar a bom termo as grandes obras é o de que se deve procurar, primeiramente, ensaiar em exemplos pequenos e mais fáceis antes de chegar-se propriamente aos temas grandiosos (Platão,1955, p.175-176). 


\section{SEGUNDA PARTE. DA ESCRITURA}

2 EB arma sua Teia Interpretante (aleatória, arbitrária, in-consciente) para Ler-Escrever uma Vidarbo, tal como a Aranha às Moscas (cf. Pignatari, 1996).

2.1 Para escapar aos Códigos Biográficos, EB atenta para os riscos da tradição: (a) estagnar vínculos entre Vida e Obra, através de conexões lineares, causais, axiológicas, psicologistas, historicistas; (b) fetichizar "descendência, fatalismo, extraordinariedade, verdade, transparência, tempo" (cf. Vilas Boas, 2008); (c) realizar biografias bisbilhoteiras, moralistas, institucionais, logocêntricas, mecanicistas, apocalípticas, militantes, aliciantes (cf. Noronha, 2001; Lejeune, 1986); (d) impregnar Bat de "pobreza intelectual”, estabelecendo um "postulado teleológico do sentido da existência, da ilusão de coerência e da construção ex post de uma necessidade dos acontecimentos"; "ilusão retrospectiva de coerência", pela "coagulação das imagens"; uma "condensação do legendário em 'traços', 'anedotas', 'idiotias”' (Boyer-Weinmann, 2005 p.56; p.52); (e) trabalhar em prol da "ilusão biográfica”: falácia de se considerar U-V como "um todo, um conjunto coerente e orientado, que pode e deve ser apreendido como expressão unitária de uma 'intenção' subjetiva e objetiva, de um projeto"; ou "preocupação de dar sentido, de tornar razoável, de extrair uma lógica ao mesmo tempo retrospectiva e prospectiva, uma consistência e uma constância”, descrevendo "relações inteligíveis, como a do efeito à causa eficiente ou final, entre os estados sucessivos, assim constituídos em etapas de um desenvolvimento necessário" (Bourdieu, 1996, p.184); (f) operar com "modelos que associam uma cronologia ordenada, uma personalidade coerente e estável, ações sem inércia e decisões sem incertezas" (Levi, 1989, p.169).

2.11 Nebulosa EB (NEB) é cultivada através da seleção, recolhimento e revalorização de resíduos difusos, excertos, cortes, hiatos, esgarçamentos miúdos, imagens inacabadas, fluidos pulsantes (sempre em vias de se mostrar), que povoam o que foi e o que não foi mostrado nas formas de "Anotação do Presente", em sua "proliferação densa": documentos pessoais, diários, depoimentos, entrevistas, memórias, confissões, correspondência, álbuns, cadernetas, fotografias, auto-retratos, testamentos, hieróglifos, etc. (cf. Barthes, 2005a p.37-38; p.154-155; p.181-225; cf. Chaia, 1996).

2.2 Leitura Bat (LB): (a) "não é um gesto parasita, o complemento reativo de uma escritura que adornamos com todos os prestígios da criação e da anterioridade"; (b) é "um trabalho", como "ato lexiológico, lexiográfico", já que escrevemos nossas leituras; (c) "trabalho, cujo método é topológico", que movimenta e desloca "sistemas cujo percurso não pára no texto nem no 'eu”" (Barthes, 1992, p.44). 
2.21 LB ocorre em "três campos de diferenças, três ordens de leituras": (A) Individual (corporal), no qual é possível ler os textos: (a) "em picada": sobrevoar a página e recolher "um sintagma saboroso, ou chocante, ou problemático, enfim, "digno de nota"; (b) "em prise": apreender, com delicadeza, uma página inteira do texto e saboreá-la; (c) "em rolo": desenrolar o Texto do início ao fim e avançar, a passos iguais sem ligar para prazer ou tédio; (d) "em aplainador": ler, em detalhe, cada palavra, sem economizar tempo, como um glosador; (d) "em céu aberto": ver o Texto, como "um objeto distante, pretexto para uma reflexão", recolocando-o na "paisagem histórica: teoria do texto, resistências, História futuro, etc.”. (B) Sociológico: neste espaço, não distinguir o Texto da sua acolhida crítica, como se esta o integrasse (C) Histórico: ler o Texto como "leitores que não vivem no mesmo tempo de leitura (mesmo se biograficamente são contemporâneos)", correndo o risco da "pulverização na História" (Barthes, 1982, p.69-72).

2.211 LB integra uma Tipologia dos Prazeres, na qual, há "três vias", cuja "Imagem de leitura" "pode capturar o sujeito-leitor": (a) Relação Fetichista: "tira prazer das palavras" ("prática oral e sonora oferecida à pulsão") e necessita de uma "vasta cultura lingüística”; (b) Relação de Desgaste: o leitor é "puxado para frente", por "uma força”, "mais ou menos disfarçada, da ordem do suspense" - "quero surpreender, não agüento esperar: pura imagem do gozo"; (c) Aventura de Escritura: "a leitura é condutora do Desejo de escrever", de modo que desejamos não "escrever como o autor cuja leitura nos agrada", mas "apenas o desejo que o escritor teve de escrever": "desejamos o ame-me que está em toda escritura" (Barthes, 2004c, p.38-40).

2.2111 LB libera-nos "de uma falsa idéia da 'objetividade", para "incluir na leitura de um texto o conhecimento que podemos ter de seu autor" (Barthes, 1982, p.71).

2.22 LB defende que: (a) quem "age o texto é o leitor", que é plural; (b) para um mesmo texto, há "uma multidão de leitores": "não só indivíduos diferentes mas também em cada corpo ritmos diferentes de inteligência, conforme o dia, conforme a página”; (c) já, "para alguns, a vida é textual”, existindo "escritores sem livros, cuja prática, linguagem, corpo, organização" nos trazem "a certeza de um verdadeiro texto", produzindo todos os "efeitos de um texto" (Barthes, 1982, p.71-72).

2.221 Decididamente, LB acontece: (a) "por cima do ombro daquele que escreve, como se nós escrevêssemos ao mesmo tempo que ele" (Barthes, 1982, p.72); (b) levantando "a cabeça o tempo todo para devanear ou refletir" sobre o que o Texto diz; (c) reencontrando, "no nível do corpo, e não do da consciência", "como aquilo foi escrito", o que implica 
colocar-se "na produção, não no produto"; (d) "ler, senão voluptuosamente, pelo menos 'apetitosamente", "fora de qualquer responsabilidade crítica": "prazer de leitura livre, feliz, guloso"; (e) ler como "verdadeiramente escrever": re-escrever o Texto lido, "melhor e mais adiante do que o seu autor o fez" (Barthes, 2004a, p.268-269; cf. 1984, p.84).

2.3 EB efetiva, assim, "anamnese factícia": (a) "recordação errática, caótica", atribuída "ao autor que amo"; (b) "ação mistura de gozo e esforço - que leva o sujeito a reencontrar sem o ampliar nem o fazer vibrar, uma tenuidade de lembrança" (como o haicai japonês); (c) quanto mais as anamneses são foscas ("insignificantes, isentas de sentido", impedindo "qualquer indução"), mais escapam "ao imaginário" (Barthes, 2003d, p.126; 2004c, p.288; cf. Martin-Achard, 2007).

2.31 Nas Vidas, o que interessa à EB: (a) "os buracos que elas comportam, as lacunas", as "catalepsias ou uma espécie de sonambulismo": "nesses buracos que se faz o movimento". A questão é "como fazer o movimento, como perfurar a parede para não dar mais cabeçadas. Talvez não se mexendo demais, não falando demais: evitar os falsos movimentos, residir onde não há mais memória” (Deleuze, 1992, p.172); (b) os "espaços vazios": "alguns pormenores", "alguns gostos", "algumas inflexões", que deambulam "fora de qualquer destino", e contagiam, "como átomos voluptuosos", "algum corpo futuro, destinado à mesma dispersão" (Barthes, 1979, p.14).
2.311 EB segue o Princípio da Vacilação do Tempo: (a) abre suas "comportas"; (b) abala a cronologia; (c) subtrai "o tempo rememorado à falsa permanência da biografia”; (d) desorganiza não "a inteligibilidade do Tempo, mas a lógica ilusória da biografia, na medida em que ela segue tradicionalmente a ordem puramente matemática dos anos"; (e) desorganiza a Biografia, o que, no entanto, "não é a sua destruição", jà que "numerosos elementos da vida pessoal são conservados", embora "desviados" (cf. Barthes, 2004c, p.354); (f) dessa maneira, "a biotópica de um Eu disperso e volátil substitui a crônica de uma identidade” (Boyer-Weinmann, 2005, p.52).

2.32 EB adota Procedimentos de Desvios: (a) Desvio do Enunciador: "o eu que escreve o texto nunca é mais do que um eu de papel” (Barthes, 2004c, p.72); "pessoa enunciadora", que põe "em cena - ou em escritura - um 'eu' (o Narrador)", que já não é mais "exatamente um 'eu' (sujeito e objeto da autobiografia tradicional)", "civil e patronímico"; não "aquele que se lembra, se confia, se confessa", senão "aquele que enuncia" - "um eu de escritura, cujas ligaçoes com o 'eu' civil são incertas, deslocadas"; (b) Desvio da Narrativa: que "não é um ensaio", "não é a de uma vida", mas a do "desejo de escrever" - o que leva Bat a lidar com "uma vida desorientada"; (c) Desvio da Vida mesma: Bat faz "biografia simbólica" ou "história simbólica da vida", que requer a escrita não de um curriculum vitae, mas de "uma constelação de circunstâncias e de figuras” (cf. Barthes, 2004c, p.354-356). 
2.4 A Natureza de EB é constituída por: (a) "fragmento, do rush": "O fragmento é seu ideal: uma alta condensação, não de pensamento, ou de sabedoria, ou de verdade (como na Máxima), mas de música" - "o fragmento é como a idéia musical de um ciclo", "intermezzo" (Barthes, 2003d, p.109110); (b) "traços biográficos": aqueles "que, na vida de um escritor", nos "encantam tanto quanto certas fotografias" - "a Fotografia tem com a História a mesma relação que o biografema com a biografia" (Barthes, 1984, p.51); (c) punctum "um detalhe, ou seja, um objeto parcial" (Barthes, ib., p.69); (d) "pontos de referência": "chamadas de atualidade, sintagmas prontos, pequenas 'condensações de saber', trechos vagamente identificáveis, lufadas de legibilidade, breves coágulos surgidos do discurso dos outros" - "rápidos alôs"; (e) nos quais, "a memória social surge, mas é para eclipsar-se logo; o plágio está quebrado, pulverizado; a memória vagueia, não fica no lugar; produz-se uma nova língua na língua, um grund, uma tela móvel, eletrificada"; (e) "lembranças de linguagem pululam, mas não param nunca, nunca são acariciadas” (Barthes, 1982, p.61-62).

2.41 EB faz do Incidente - "menos contundente que o acidente, mas mais inquietante" - a Unidade Atratora de suas experimentações: (a) "Incidentes (minitextos, recados, haicais, anotações, jogos de sentido, tudo o que cai, como uma folha, etc.)" (Barthes, 2003d, p.167); (b) “promoção amorosa daquilo que geralmente se toma por um pormenor insignificante, um elemento constitutivo da transferência (ou da paixão): a parcialidade"; (c) "pormenores precisos" e, ao mesmo tempo, descontínuos irregulares, interrompidos, intermitentes (cf. Barthes, 2004c, p.372); (d) "aquilo que tomba, mas também que sobrevive"; (e) "pequenas cenas, estilhaços de romance", "estilhaços de linguagem": "nem esboços, nem anotações, nem materiais, nem exercícios"; (f) "não de fragmentos, mas de incidentes, coisas que caem, sem choque, e no entanto com um movimento que não é infinito: contínuo descontínuo do fluxo de neve" (Barthes, 2004c, p.282-284); (g) frutos do Satori (Zen), da Kairós (céticos), da Epifania (Joyce), do Momento de Verdade (Proust), do Instante Pleno (Diderot), os Incidentes de Bat captam "um fragmento de presente", "ao vivo", "o cume do particular", uma "picada essencial", "com-presença”, "ligação instantânea", que indica "retorno da letra"; (h) enquanto "redenção da língua", atinente à "poética antimoderna da presença": "simples, filial, desejável" (cf. Barthes 2005a,b; 2007, p.101-108); (i) "cada incidente da vida pode dar azo ou a um comentário (uma interpretação) ou a uma fabulação que lhe dá ou lhe imagina um antes e um depois narrativos"; (j) "ligar os incidentes, as impressões, desenvolvê-los" é "tecer pouco a pouco uma narrativa, ainda que frouxa" (Barthes, 2004c, p.350; p.289)

2.411 EB comporta os seguintes Traços Estilísticos: aventuras infinitesimais; incongruência mínima; rápido deslocamento na apreensão do cotidiano; detalhe que toca; 
acontecimento minúsculo; impressão breve; diálogos descontínuos e rápidos (máximo: duas réplicas); dobra sutil no tecido dos dias; um modo menor (em linguagem musical: "enunciações, não argumentos, 'toques”'), face ao acontecimento forte (midiático, político); indiferenciação temporal que abole a noção de duração e introduz uma temporalidade cíclica, ritual (como a alternância das estações no haicai) sobredeterminação espacial, que elimina a distância entre Enunciação e Enunciado, criando um efeito de simultaneidade entre Incidente e Anotação; forma de escrita de um Presente Absoluto, em Notação Grau Zero, necessária para escrever: "faz da linguagem a frágil salvação de certo sofrimento" (cf. Barthes, 1988; 2004c, p.66; p.283).

2.5 EB persegue "a arte do retrato em pintura": executa "retratos mentais, conceituais", "por meios que não sejam semelhantes, por meios diferentes", nos quais a semelhança é produzida e não "um meio para reproduzir" - "aí nos contentaríamos em redizer o que o filósofo disse" (Deleuze, 1992, p.169).

2.51 Para realizar Retratos em Movimento, EB vivifica corpos pela e na linguagem, introduzindo, em U-V, a "dimensão carnavalesca": contra Histórias de Vida, Narrativas Autobiográficas, Totalidade, Fidelidade, Autocontrole (Barthes, 1982, p.78). Usa antes o imaginário do que os fatos Incide o desconhecido, suspeito, lacunar, ausente, sub-reptício, negado, interditado. Surpreende estados intervalares.
Evidencia Nuances contra "formas de pensamento pronto, rígido, uniforme", que repetem "falsas evidências" (Pierre, 2006, p.48). Trabalha com enigmas latentes, entre os pólos da Vida e da Obra. Desvincula componentes de suas zonas de pertencimento. Transfere componentes de uma instância para outra, e vice-versa. Através de "erotografia", "autobiografema", "autobiograficção" e "cartografemática" (cf. Barthes, 1979, p.127-128, p.139-140, p.160; 1984, p.173175; 1988; Eiró, 2008, p. 23; p.85), EB faz "antibiografia”: o Biografematizado (Baz) é visto como "estrutura estelar repleta de desvãos que escondem as faces perdidas e na qual os signos equivalentes estão soltos para pontilharem outros rostos" (Noronha, 2001, p.10; p.11). Em diálogo escritural de montagem e composição, recolhe pedaços, como molas propulsoras, refeitas no ato ficcional. Desenha máscaras trocadas. Identifica ardis romanescos, que jazem ocultos nas franjas do vivido. Acha que decifra pulsões desejantes. Constrói uma imagem cambiante de Baz: "falo de mim como se estivesse um pouco morto, preso numa leve bruma de ênfase paranóica" (Barthes, 2003d, p.186).

2.6 EB é sensual: (a) exercita ausência de palavra para forçar "a passagem dos objetos sensuais dentro do discurso", de modo que "a substância sensual das coisas" leva "a linguagem a dispor em seu tecido alguns efeitos físicos, algumas metonímias", "algumas lembranças (táteis, voluptuosas, saborosas)"; (b) integra "passagens", que são sempre "legíveis" 
("se você quiser ser lido escreva de maneira sensual"), tais como: em Chautebriand, "as laranjeiras da Vida de Rance", em Bataille, "o prato de leite da História do olho"; em Hegel, "a plumagem da coruja" de Minerva, a qual, "só no início do crepúsculo", "alça seu vôo"; em Marx, "a silhueta do tecelão e do entalhador" (cf. Barthes, 1982, p. 62-63).

2.61 Como na obra de Sade, EB providencia que: (a) a "Cena" ou "Sessão" funcionem e delas nasça impressão de Performance; (b) o "Quadro" componha-se; (c) a "Posição" reúna Ação e Ponto de Aplicação; (d) o "Código" seja organizado pelas menores Unidades; (e) os "Operadores" estejam formados por Posiç̃os combinadas; (f) o "Episódio" encontre-se entre duas Fruições; (g) as "Figuras" sejam feitas diacronicamente, por sucessão de Posições e adquiram o "sentido ginástico ou coreográfico"; (h) a "Sintaxe" procure a "Figura Total"; (i) as "Regras de Ação" sejam seguidas; (1) o "Discurso" erotize; (m) todas as "Unidades" submetam-se a Regras de Composição ou de Combinação, que acontecerão até o Infinito (cf. Barthes, 1979, p.122-166; 1989b, p.1-3; p.94-96; Feil, 2009)

2.7 EB é Rapsódia de Vida: (a) sem "respeito pelo todo", reduz o universo "a migalhas" e "sistemas de instantes" (Barthes, 2004c, p.353); (b) "costurada", "como um vestido", compõe uma "arte original, como é a da costureira: peças, pedaços são submetidos a cruzamentos, a arranjos, a ajustes"; (c) seus "fragmentos intelectuais ou narrativos" formam "uma sequeência que se subtrai à lei ancestral da Narrativa ou do Raciocínio", produzindo "a terceira forma, nem Ensaio, nem Romance” (cf. Barthes, ib., p.353-355).

2.71 EB é "Estroboscópica": "a narrativa se anima", "os di ferentes temas entram em conexão e as palavras formam figuras variadas segundo as precipitadas velocidades de leitura e de associação" (Deleuze, 2006c, p.293).

2.711 EB usa: (A) Hipotipose: (a) "uma certa filosofia do objeto", "iconografia autônoma do objeto"; (b) "um flash do referente"; (c) "espécie de visão subliminar"; (d) "palavra [que] faz ver rapidamente"; (e) "passagem do tangibile" ("o que pode ser tocado, palpável"); (f) "força de visão (de quadro)", "curtas seqüências filmadas"; (g) "descrição animada, viva e impressionante, que coloca, por assim dizer, a coisa sob os olhos" (cf. Barthes, 1979; 2004c, p.104; 2005a, p.117-134). (B) (a) Fanopéia: "imagem (flash) visual, feita de impactos olho-coisa”; (b) Melopéia: saturação da palavra "de um som", ou uso de "grupos de palavras para obter esse mesmo efeito"; (c) Logopéia: "dança do intelecto entre as palavras", usadas "numa relação especial ao 'costume", "ao tipo de contexto em que o leitor espera ou está habituado a encontrá-las" (cf. Campos, 1967, p.25; Campos, 1972, p.63; Campos, 1986, p.22-23; Pound, 2006, p.41; p.53; p.61).

2.7111 EB assume o "Método da Dramatização", ou "Método de Nietzsche", o qual indaga pelas Forças e pela Vontade de 
Potência que atribuem sentido a U-V: (a) em vez de perguntar Que é? (pergunta metafísica pela essência platônica)

(b) indaga: Quem? Quanto? Como? Onde? Quando? Em que caso? (c) segue Nietzsche: "O quê? perguntava-me com curiosidade. - Quem? Deverias tu interrogar-te! Assim fala Dioniso" (Nietzsche apud Monteiro e Biato, 2008, p.268; cf. Deleuze, 1976, p.60-65; 2006a).

2.8 Desse modo, EB coloca o próprio Bo "em estado de desejo, de prazer projetado” (Barthes, 2005a, p.117).

$\$ 4^{\circ}$. Quer se trate dos menores ou dos mais sublimes efeitos, do choque e da gravidade, quer do pensamento e da moralidade, deles não podemos conhecer realmente senão as diversas ligações mútuas próprias à sua realização, sem nunca penetrar o mistério da sua produção (Comte, 1976, p.17).

\section{TERCEIRA PARTE. DE VIDARBO}

$\$ 5^{\circ}$. O poeta é imitador, como o pintor ou qualquer outro imagi nário; por isso, sua imitação incidirá num destes três objetos: coisas quais eram ou quais são, quais os outros dizem que são ou quais parecem, ou quais deveriam ser. Tais coisas, porém ele as representa mediante uma elocução que compreende palavras estrangeira e metáforas, e que, além disso, comporta múltiplas alterações, que efetivamente consentimos no poeta (Aristóteles, 1966, p.99).

Vidarbo: Vida + Obra. "Circulação igual dos códigos com os quais se escrevem ao mesmo tempo nossos livros e nossa vida”. Viver como quem escreve. Escrever vivendo. Viver escrevendo. Re-viver. Re-finar. "Pensar a biografia contra a biografia”. Fluido. Elipse. Mistério. Inteligibilidade do desejo. Metáfora infinita. "Geologia de escrituras psicológicas". Fabulação de gostos, des-gostos, descobertas, sensibilidade, estados d'alma, imagens, poses, figuras, músicas, afectos. Como é, Para Mim - o que não fala, sem alegar a si mesmo, condenado ao exílio da Generalidade. Transliteração: "mudar o livro" é "mudar a vida". Cenografia espaço-temporal. Nos passeios da Vida, aparição de Temas. Nos passeios das Palavras, aparição de Personagens. Ações que se pode tocar, na retina. Aromas ávidos no ar. Prazeres intensos. Pensares apanhados. Quereres guardados. Sentires desovados. Na Magia de ler, fascínio de limites se rompendo. Voz do Sujeito-de-Escritura: escrever o que não pôde dizer. Grãos de sentidos, na pele do Eu-de-Papel, após travessia do deserto, caminhada à beira-mar. "Nossos mares se molham e espantam as securas que os dias nos trazem". Cruel desafio à interpretação. Fundos de Silêncio. Habitante dos Interstícios. Assombrado. Sem economia de Bem e Mal. Não-lucro. "Luxo terno e suntuoso de uma escritura absolutamente livre, em que não há um único átomo morto, invulnerável de tanta graça”. Pulsão por des-formas. Breves. "Têm o comprimento e o impulso da linha (essa idéia vestimentar)". Non multa, sed multum (pouco em quantidade, muito em qualidade). Radicalização na preparação. Sem salvaguarda. Munição impaciente. Anarquicamente debochada. "Ervinhas frescas". 
Atravessar, navegar, saltar: e pronto. Corda bamba, sem sombrinha, embriagado. Pronto. Cair. Se for o caso. Pronto.

Ver, sentir, amar, odiar, chorar, ter cefaléia, sede, fome, saudade. Avaliar valor dos largados. Desgarrados. Simulacro de Romance. Romanesco Anamnésico. "Fresco, simples, sedoso, leve, sensível, justo, inteligente, desejável, forte, rico". Hábitos, manias, vícios: contestados. Paixão por perturbação, motilidade, leveza. Sem pessoa. Caleidoscópio insólito. Estranho dissonante. "Profunda amoralidade". Conta-dor de histórias. Linguaja-dor de si. Faze-dor de jogo. Gagueja-dor de língua. Bolas de emoção. Roçadela. Fricção. "Isso granula, isso acaricia, isso raspa, isso corta: isso frui”. Como se vê, Bat inunda Vidas. Minha. Tua. Nossa. Por isso, IMB pode colocar "no topo aqueles capazes da risada de ouro": "rir de maneira nova e sobre-humana - e à custa de todas as coisa sérias". É que os "deuses gostam de gracejos: parece que mesmo em cerimônias religiosas não deixam de rir" (Nietzsche, 1992, p.195; cf. Barthes, 1982, p.22; 2006, p.19-20; p.78 2004c, p.283-284; p.292; Costa, 2008, p.15; Fonseca, 2009).

$\S 6^{\circ}$. A verdadeira eloqüência zomba da eloqüência, a verdadeira moral zomba da moral; quer dizer que a moral do juizo zomba da moral do espírito, que não tem regras. Pois é ao juízo que pertence o sentimento, como as ciências pertencem ao espírito. A finura é a parte do juizo, a geometria, a do espírito. Zombar da filosofia é, em verdade, filosofar (Pascal, 1979, p.39).

\section{QUARTA PARTE. DAS REFERÊNCIAS}

ABBAGNANO, Nicola. Dicionário de filosofia. São Paulo: Mestre Jou, 1970, p.640-641. (Trad. Alfredo Bosi.)

ARISTÓTELES. Poética. Porto Alegre: Globo, 1966. (Trad. Eudoro de Sousa.

BARTHES, Roland. Sade, Fourier, Loiola. Lisboa: Edições 70, 1979. (Trad. Maria de Santa Cruz.)

Sollers escritor. Rio de Janeiro: Tempo Brasileiro; Fortaleza: UFC, 1982. (Trad. Lígia Maria Ponde Vassallo.)

A câmara clara: nota sobre a fotografia. Rio de Janeiro: Nova Fronteira, 1984. (Trad. Júlio Castañon Guimarães.)

Incidentes. Rio de Janeiro: Guanabara, 1988. (Trad. Júlio Castañon Guimarães.)

Aula (pronunciada dia 7 de janeiro de 1977). São Paulo: Cultrix 1989a. (Trad. Leyla Perrone-Moisés.)

. Fragmentos de um discurso amoroso. Rio de Janeiro: Francisco Alves, 1989b. (Trad. Hortência dos Santos.)

Michelet. São Paulo: Companhia das Letras, 1991. (Trad. Paulo Neves.)

S/Z. Rio de Janeiro: Nova Fronteira, 1992. (Trad. Léa Novaes.) 
Como viver junto: simulações romanescas de alguns espaços cotidianos: cursos e seminários no Collège de France, 1976-1977. São Paulo: Martins Fontes, 2003a. (Trad. Leyla Perrone-Moisés.)

Crítica e verdade. São Paulo: Perspectiva, 2003b. (Trad. Leyla Perrone-Moisés.)

O neutro: anotações de aulas e seminários ministrados no Collège de France, 1977-1978. São Paulo: Martins Fontes, 2003c. (Trad. Ivone Castilho Benedetti.)

Roland Barthes por Roland Barthes. São Paulo: Estação Liberdade, 2003d. (Trad. Leyla Perrone-Moisés.)

O grão da voz: entrevistas, 1962-1980. São Paulo: Martins Fontes, 2004a. (Trad. Mario Laranjeira.)

O grau zero da escrita: seguido de novos ensaios críticos São Paulo: Martins Fontes, 2004b. (Trad. Mario Laranjeira.)

O rumor da língua. São Paulo: Martins Fontes, 2004c. (Trad. Mario Laranjeira.)

A preparação do romance I: da vida à obra. Notas de cursos e seminários no Collège de France, 1978-1979. São Paulo: Martins Fontes, 2005a. (Trad. Leyla Perrone-Moisés.)

A preparação do romance II: a obra como vontade. Notas de curso no Collège de France 1979-1980. São Paulo: Martins Fontes, 2005b. (Trad. Leyla Perrone-Moisés.)

O prazer do texto. São Paulo: Perspectiva, 2006. (Trad. J. Guinsburg.)
O império dos signos. São Paulo: Martins Fontes, 2007. (Trad. Leyla Perrone-Moisés.)

Sobre Racine. São Paulo: Editora WMF Martins Fontes, 2008. (Trad. Ivone C. Benedetti.)

BOYER-WEINMANN, Martine. La relation biographique: enjeux contemporains. Paris: Champ Vallon, 2005.

BOURDIEU, Pierre. "A ilusão biográfica" in FERREIRA, Marieta de Morais; AMADO, Janaína (orgs). Usos e abusos da história oral Rio de Janeiro: Editora FGV, 1996, p. 183-191.

BRUGGER, Walter. Dicionário de filosofia. São Paulo: Herder, 1962. p.345-346. (Trad. Antônio Pinto de Carvalho.)

CAMPOS, Augusto. O anticrítico. São Paulo: Companhia das Letras, 1986

CAMPOS, Haroldo de. Metalinguagem: ensaios de teoria e crítica literária. Petrópolis, RJ: Vozes, 1967.

\section{A arte no horizonte do provável e outros ensaios. São} Paulo: Perspectiva, 1972

CHAIA, Miguel. "Biografia: método de reescrita da vida" in HISGAIL, Fani (org.). Biografia: sintoma da cultura. São Paulo: Hacker Editores; Cespuc, 1996 (p.75-82)

COMTE, Augusto. Discurso sobre o espírito positivo: ordem e progresso. Porto Alegre, Globo; São Paulo, Editora da USP, 1976. (Trad. Renato Barbosa Rodrigues Pereira.) 
COSTA Luciano Bedin da. A vida em escrileitura: biografemas e o problema da biografia. Porto Alegre, RS: PPGEDU/UFRGS junho 2008. Proposta de Tese de Doutorado, 186p. (Texto dig.)

DELEUZE, Gilles. Nietzsche e a filosofia. Rio de Janeiro: Editora Rio, 1976. (Trad. Edmundo Fernandes Dias e Ruth Joffily Dias.)

Conversações, 1972-1990. Rio de Janeiro: Ed. 34, 1992 p.169-193. (Trad. Peter Pál Pelbart.)

A filosofia crítica de Kant. Lisboa: Edições 70, 1994. (Trad. Germiniano Franco.)

Lógica do sentido. São Paulo: Perspectiva, 1998, p.311-330 (Trad. Luiz Roberto Salinas Fortes.)

"O método da dramatização" in ORLANDI, Luiz B.L. (org.). A ilha deserta: e outros textos. São Paulo: lluminuras, 2006a p.129-154. (Trad. Luiz B.L.Orlandi.)

"Em que se pode reconhecer o estruturalismo"? in ORLANDI, Luiz B L (org) A ilha deserta: e outros textos. São Paulo: Iluminuras, 2006b, p.221-247. (Trad. Hilton F. Japiassu.)

"Hélène Cixous ou a escrita estroboscópica" in ORLANDI, Luiz B.L. (org.). A ilha deserta: e outros textos. São Paulo: lluminuras, 2006c, p.293-294. (Trad. Fabien Lins.)

"A imanência: uma vida..." in "Dossiê Deleuze e a Educação". Educacão \& Realidade Porto Alegre v 27, n. 2 julho-dezembro 2002, p.10-18. (Trad. Tomaz Tadeu.)
DESCARTES. Discurso do método: para bem conduzir a

própria razão e procurar a verdade nas ciências in _. Obra escolhida. São Paulo: Difusão Européia do Livro, 1962a, p.40103. (Trad.J. Guinsburg e Bento Prado Júnior.)

Meditações in . Obra escolhida. São Paulo: Difusão Européia do Livro, 1962b, p.105-199. (Trad.J. Guinsburg e Bento Prado Júnior.)

EIRÓ, Jorge. Cartografemas: fragmentos autobiográficos de um artista-professor. Belém, Pará: PPGEDU/UFPA. Dissertação de Mestrado, maio 2009، 140p. (Texto dig.)

FABBRINI, Regina. "Das linhas incertas onde a vida se inserta" in HISGAIL, Fani (org.). Biografia: sintoma da cultura. São Paulo: Hacker Editores: Cespuc, 1996 (p.63-73).

FEIL, Gabriel Sausen. Procedimento erótico, na formação ensino, currículo. Porto Alegre, RS: PPGEDU/UFRGS, janeiro 2009. Tese de Doutorado, 245p. (Texto dig.)

FEYERABEND, Paul Contra o método. Rio de Janeiro: Francisco Alves, 1989. (Trad. Octanny S. da Mota e Leonidas Hegenberg.)

FONSECA, Tania Mara Galli. Correspondência pessoal. Porto Alegre, 20, 21 maio 2009.

LALANDE, André. Vocabulário técnico e crítico da filosofia. São Paulo: Martins Fontes, 1999, p.678-680. (Trad. Fátima Sá Correia et alii.)

LEJEUNE, Philippe. Moi aussi. Paris: Éditions du Seuil, 1986 
LEVI, Giovanni. "Usos da Biografia" in FERREIRA, Marieta de Moraes; AMADO, Janaína (orgs.). Usos e abusos da história oral. Rio de Janeiro: Editora FGV, 1996, p.167-182.

MARTIN-ACHARD, Frédéric. "'Le nez collé à la page': Roland Barthes et le roman du présent" in http://trans.univ-paris3.fr/

Trans - No 3: Écrire le present. Hiver 2007. (Capturado em julho 2008.)

MONTEIRO, Silas Borges; BIATO, Emília Carvalho L. "Uma avaliação crítica acerca de método e suas noções" in Revista de Educação Pública. Cuiabá: maio/ago. 2008, v.17, n.34, p.255-271.

NIETZSCHE, Friedrich Wilhelm. Além do bem e do mal: prelúdio a uma filosofia do futuro. São Paulo: Companhia das Letras, 1992. (Trad. Paulo César de Souza.)

Ecce homo: como alguém se torna o que é. São Paulo: Companhia das Letras, 1995. (Trad. Paulo César de Souza.)

NOLASCO, Edgar Cezar. Restos de ficção: a criação biográficoliterária de Clarice Lispector. São Paulo: Annablume, 2004.

NORONHA, Luzia Machado Ribeiro de. Entreretratos de Florbela Espanca: uma leitura biografemática. São Paulo: Annablume Fapesp, 2001.

OLIVEIRA, Marcos da Rocha. Biografemática de um educador Porto Alegre, RS: PPGEDU/UFRGS, dezembro 2008. Proposta de Dissertação de Mestrado, 118p. (Texto dig.)

PASCAL, Blaise. Pensamentos. São Paulo: Abril Cultural, 1979 (Trad. Sérgio Milliet.)
PLATÃO. O sofista in Diálogos Il volume: Fédon, Sofista Político. Rio de Janeiro; Porto Alegre; São Paulo: Globo, 1955 p.171-263. (Trad. Jorge Paleikat e Cruz Costa.)

PIERRE, Jean-. Roland Barthes: dernier paysage. Lille, FR: Éditions Verdier, 2006.

PIGNATARI, Décio. "Para uma semiótica da biografia" in HISGAIL, Fani (org.). Biografia: sintoma da cultura. São Paulo: Hacker Editores; Cespuc, 1996 (p.13-19).

POUND, Ezra. ABC da literatura. São Paulo: Cultrix, 2006. (Trad. Augusto de Campos e José Paulo Paes.)

RIBEIRO, Renato Janine. "A política de Don Juan" in _org.). A sedução e suas máscaras:ensaios sobre Don Juan. São Paulo: Companhia das Letras, 1988, p.9-21.

VILAS BOAS, Sergio. Biografismo: reflexões sobre as escritas de vida. São Paulo: Editora UNESP, 2008

WITTGENSTEIN, Ludwig. Tractatus logico-philosophicus. São Paulo: Editora da USP, 1993. (Trad. Luiz Henrique Lopes dos Santos.) 